\title{
Editorial 54
}

\author{
Eric Scerri ${ }^{1}$
}

Published online: 6 October 2016

(C) Springer Science+Business Media Dordrecht 2016

It is with great regret that I must announce the passing of another member of our community, the Japanese historian of science and Mendeleev expert, Masanori Kaji. Masanori always impressed everyone with his courtesy and deep knowledge of the topics on which he wrote and spoke and he will be sorely missed. I leave it to his friend and collaborator Yona Seiderer to say more about him in her accompanying obituary that follows.

The papers in this issue begin with Amihud Gilead, a philosopher from Israel who considers elements and the periodic table in order to discuss a notion that he calls chemically pure possibilities. Among other claims, Gilead suggests that the existence of eka-elements such as those postulated by Mendeleev and others cannot be considered as actual but only as "purely possible".

Mark Weinstein from Montclair University in New Jersey also focuses on the steps that led to the periodic table and considers its eventual explanation through quantum mechanics to be the most successful example of scientific enquiry in the history of science. His main aim is to attempt to capture the epistemological aspects that warrant truth claims based on models that are progressive in terms of theoretical and empirical advances.

Peter Muursepp writes from the University of Tallin in Estonia. His paper provides an exposé of 'practical realism' as first proposed by another Estonian philosopher of chemistry, the late Rein Vihallen. In addition Muursepp considers a classic article by Edward Caldin who was working in what was effectively the philosophy of chemistry well before this became an established field in the mid 1990s. Incidentally I would strongly urge readers of this journal to go back and study the one or two articles of this genre that Caldin produced. ${ }^{1}$

Olimpia Lombardi and her colleagues Fortin and Martinez Gonzales, who are based in Buenos Aires, present an article of quantum decoherence in relationship to the topic of

\footnotetext{
${ }^{1}$ E.F. Caldin, The Structure of Chemistry in Relation to the Philosophy of Science, Hyle, 8(2), 103-121, 2002.
}

Eric Scerri

scerri@chem.ucla.edu

1 UCLA, Los Angeles, CA, USA 
optical isomerism. Although the authors are too polite to say so directly, their article appears to be partly an attempt to refute my claim that decoherence removes some of the apparent mysteries about molecular structure that authors such as Woolley and Hendry have claimed. The trio of Argentinian authors provide a thorough mathematical account of the fact that decoherence does not fully solve the collapse problem in quantum mechanics. As they correctly point out, the question of optical isomerism and the apparent failure of quantum mechanics to differentiate between the two isomers of any particular optically active compound is quite independent of the Born-Oppenheimer approximation. This is due to the fact that the two isomers share precisely the same molecular shape including bond angles and bond lengths. One might almost say that they have the same structure apart from not sharing the same handedness.

The final full-length article is by Grant Fisher who is currently based in South Korea and whose research has previously focused on chemical explanations and the use of models in chemistry. In his paper Fisher examines the kinds of calculations carried out in the field of computational organic chemistry. The author's aim is to highlight what he calls the pluralism in the various approaches used in the case of pericyclic reactions. As Fisher reports these calculations are approached via ab initio methods, as well as various semi-empirical approaches that import experimental data into their work rather than attempting to compute everything from first principles. 